\title{
Neonatal Onset Glaucoma in a Case with Gorlin-Goltz Syndrome: An Unusual Association
}

\author{
AB Tefon Arıbaş ${ }^{1}$, Zeynep Aktaş ${ }^{2}$, Şengül Özdek ${ }^{3}$
}

\begin{abstract}
Aim and objective: To report a unique presentation of Gorlin-Goltz syndrome (GGS) with congenital glaucoma.

Materials and methods: We report a case of a 3-month-old female patient with bilateral uncontrolled intraocular pressures (IOP), who was already diagnosed with GGS. Examination under anesthesia demonstrated microcornea, iris coloboma, lens subluxation in both eyes, and edematous cornea in the left eye. Intraocular pressure was $17 \mathrm{~mm} \mathrm{Hg}$ in OD and $35 \mathrm{~mm} \mathrm{Hg}$ in OS with Icare (Icare ${ }^{\circledR}$ PRO) tonometer on repetitive measurements. On dilated fundus examination, a large chorioretinal coloboma was seen on both eyes.

Results: On physical examination, cutaneous, dental, and skeletal anomalies associated with the GGS were found. As previously reported ocular abnormalities associated with the GGS; coloboma and microphthalmia were noted. In addition, congenital glaucoma which is not one of the known associations of GGS was also detected. For treatment, $270^{\circ}$ transscleral diode cyclophotoablation was performed for the left eye and medical treatment was reorganized for both eyes.

Conclusion: Neonatal-onset glaucoma might be one of the important ocular manifestations of GGS.

Keywords: Coloboma, Glaucoma, Gorlin-Goltz Syndrome.

Journal of Current Glaucoma Practice (2021): 10.5005/jp-journals-10078-1308
\end{abstract}

\section{INTRODUCTION}

Gorlin-Goltz syndrome (GGS-also known as basal cell nevus syndrome or nevoid basal cell syndrome) is a multi-system disorder with cutaneous, ocular, dental, and skeletal anomalies due to dysplasia of mesoectodermal-derived tissues., ${ }^{1,2}$ Jarisch and White first reported the syndrome in $1894 .^{3}$ Then, James Gorlin and William Goltz described the classic triad in 1960 with numerous basocellular epitheliomas, jaw bone keratocysts, and bifid ribs. ${ }^{4,5}$

Multiple odontogenic keratocysts (OKCs) (75\%), BCC (50-97\%), bifid ribs (40\%), palmar and plantar pits (60-90\%), and ectopic calcification of falx cerebri (37-79\%) are characteristic features of this syndrome. ${ }^{6}$ The prevalence of GGS is between $1 / 57,000$ and $1 / 256,000$, which varies greatly by region and ethnicity. ${ }^{7}$

Although sporadic cases have been found, this syndrome is an autosomal dominant inherited disorder with high penetrance and variable expressivity caused by mutation of the PORCN gene which encodes important proteins for the WNT signaling pathway. ${ }^{1}$ Forty percent of affected patients have been reported to have ophthalmologic manifestations of the disease. ${ }^{8,9}$ Reported ocular manifestations of GGS include anophthalmos, microphthalmos, ectropion, hypertelorism, strabismus, nystagmus, coloboma of retina and choroid, aniridia, cataract, epiretinal membranes, combined hamartomas, retinal pigmentary changes, papillomas of the conjunctiva and eyelid, abnormality of lacrimal apparatus, and blocked lacrimal drainage. . $^{5-12}$

Although glaucoma has been rarely reported as an ocular manifestation of GGS previously, to the best of our knowledge, association of neonatal-onset glaucoma has not been reported in the literature. ${ }^{13,14}$ In this report, we describe an unusual presentation of GGS with congenital glaucoma in a 3-month-old girl.

\footnotetext{
${ }^{1}$ Department of Ophthalmology, Gaziantep Abdulkadir Yüksel State Hospital, Gaziantep, Turkey

2,3 Department of Ophthalmology, Gazi University School of Medicine, Ankara, Turkey
}

Corresponding Author: $A B$ Tefon Arıbaş, Department of Ophthalmology, Gaziantep Abdulkadir Yüksel State Hospital, Gaziantep, Turkey, Phone: +905303632357, e-mail: burcintefon@ gmail.com

How to cite this article: Tefon Arıbaş AB, Aktaş Z, Özdek Ş. Neonatal Onset Glaucoma in a Case with Gorlin-Goltz Syndrome: An Unusual Association. J Curr Glaucoma Pract 2021;15(2):99-101.

Source of support: Nil

Conflict of interest: None

\section{Case Description}

A 3-month-old female patient with bilateral uncontrolled intraocular pressures (IOP) was referred to our clinic for further investigation and surgical management. She was on topical betablocker treatment twice daily, already diagnosed with GGS, and reported to have ears malformation, cutis aplasia, frontal bossing, cleft lip and palate, syndactyly of hands, nail dystrophy, umbilical hernia, syndactyly of feet split foot malformation, fibromas on extremities, and dermal hypoplasia (Fig. 1).

The patient was born in a non-consanguineous marriage in the 40th week of gestation and delivered by the Caesarian section. Her birth weight was 3,050 g. Her mother's obstetrical history was negative for any autoimmune or infectious diseases and no was medication taken during pregnancy. She had one healthy sister.

An examination under anesthesia was performed. The patient had hypertelorism. Microcornea was significant on both eyes 

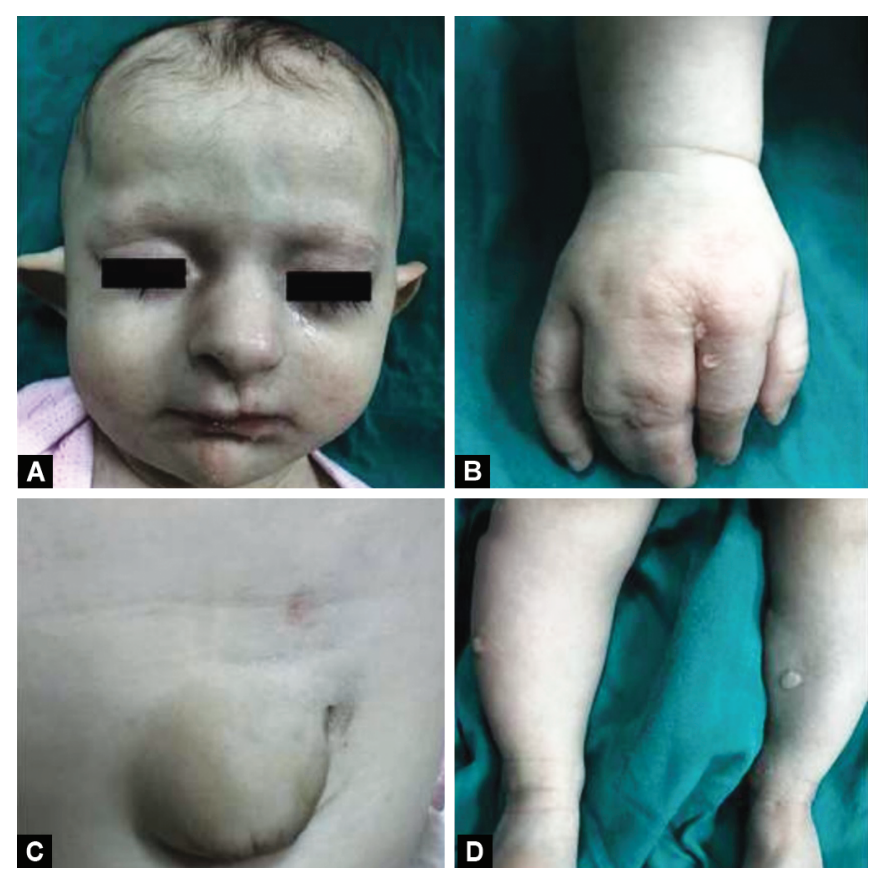

Figs 1A to D: Photographs of patient's body malformations: (A) Ears malformation, cutis aplasia, cleft lip and palate, frontal bossing; (B) Syndactyly of hand, nail dystrophy, and skin abnormalities; (C) Umbilical hernia; (D) Syndactyly of feet, split foot malformation, and fibromas on extremities
$(7.5 \times 7.5 \mathrm{~mm}$ in diameter in the right eye and $9.0 \times 8.0 \mathrm{~mm}$ in the left eye). The cornea was edematous and hazy in OS whereas it was clear in OD. Intraocular pressure was $17 \mathrm{~mm} \mathrm{Hg}$ in OD and $35 \mathrm{~mm} \mathrm{Hg}$ in OS with Icare (Icare ${ }^{\circledR}$ PRO) tonometer on repetitive measurements. Axial lengths were $18.10 \mathrm{~mm}$ in OD and $21.00 \mathrm{~mm}$ in OS (compatible with microphthalmos). Approximately $270^{\circ}$ iris colobomas were observed bilaterally and some iris tissues were present at the superior quadrant. Inferonasal lens subluxation in both eyes was observed. On dilated fundus examination, nearly total chorioretinal coloboma involving macular area was seen, although optic disk was normal in the right eye. Large chorioretinal coloboma involving the entire macula with small retinal tissue preserved in the superonasal quadrant was also noted in the left eye but the left fundus could not have been seen due to corneal clouding (Fig. 2).

$270^{\circ}$ transscleral diode cyclophotoablation was performed in the left eye and topical Brinzolamide-Timolol Maleat two times daily treatment was added to topical betaxolol that she was already using.

\section{Discussion}

Gorlin-Goltz syndrome has known to be caused by PORCN gene mutations that may alter the protein's structure, leading to the production of an abnormally short version of the protein, or deletion of the entire PORCN gene. All of these mutations appear to result in the absence of any functional PORCN protein. It is believed that WNT proteins cannot be released from the cell without the
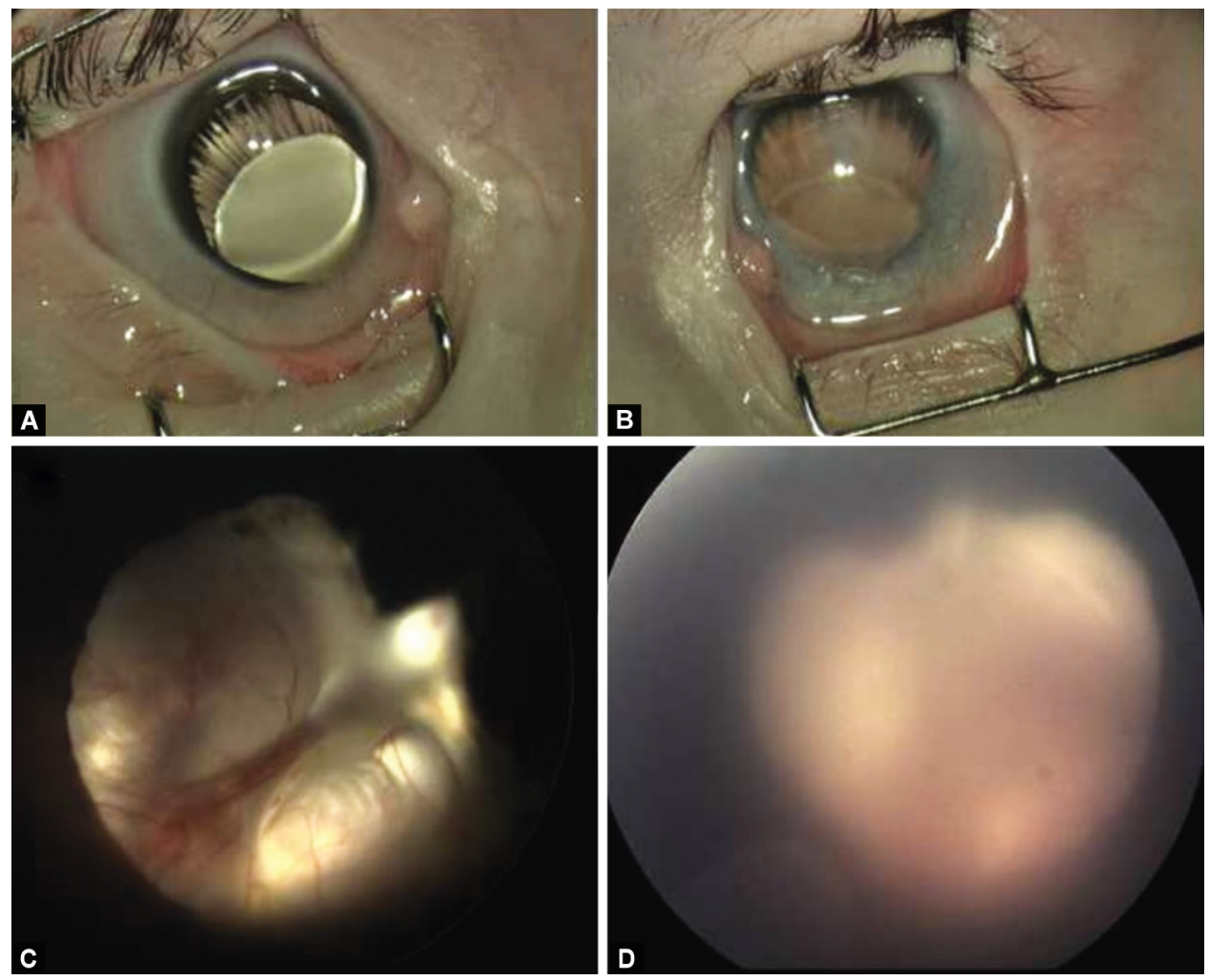

Figs 2A to D: Anterior chamber and fundus photography of patient: (A) On the right eye, the cornea is seen clearly. Nearly total iris coloboma and lens subluxation are remarkable; (B) On the left eye, corneal haze, iris coloboma, and lens subluxation are seen; (C) Retcam photograph of the right fundus. Nearly total chorioretinal coloboma involved macular are with the normal optic disk is seen; (D) Retcam photograph of the left fundus. Due to corneal clouding imaging is not clear but chorioretinal coloboma can be observed 
PORCN protein. WNT signaling is so important because it regulates the proliferation of cells. Approximately $90 \%$ of $\mathrm{FDH}$ cases are female because the disease is presumed to be lethal especially in males, although mosaic males may survive.,15 Our case had presented similar phenotypical manifestations like syndactyly, split foot malformation, fibromas on extremities, nail dystrophy, cutis aplasia, dermal hypoplasia which are typical of severe presentation patterns.

Previous publications reported that $40 \%$ of GGS patients have an ophthalmologic manifestation of the disease. ${ }^{8,9}$ However, in some recent studies, ophthalmologic involvement in GGS are reported to be much higher, such as Gisseman et al. reported in case series with 18 GGS patients with ocular involvement (77\%) in 2016 , and pointed out that the most common ocular finding was chorioretinal (61\%) and iris colobomas (50\%). ${ }^{16}$ In that study, all of the iris and chorioretinal colobomas localized inferiorly and almost half of them were bilateral. The second common manifestation was microphthalmia (44\%). Our patient had similarities with this study. She had bilateral inferior iris, large chorioretinal colobomas, and microphthalmia. Additionally, she had lens subluxation in both eyes.

Glaucoma in GGS was reported in only a few cases in the literature. However, as far as we know, all the reported cases are adults and no evidence was found associated with a neonatalonset presentation in these cases. ${ }^{13,14}$ The reported patients have well-controlled IOP with topical medications and one case has only suspect glaucoma. Our case was different from the reported cases with the presentation age and more severe glaucomarelated findings. Aniridia-associated glaucoma incidence has been reported as $6-75 \% .{ }^{17}$ Progressive anterior rotation of the rudimentary iris, leading to angle closure is responsible for the pathogenesis of the disease. Another type of glaucoma that can be seen with coloboma is pigmentary glaucoma. Coloboma-associated pigmentary glaucoma is usually seen in myopic patients, with increased axial length and concave iris configuration. ${ }^{18}$ In our case, the presence of glaucoma associated with coloboma was remarkable, also associated iridocorneal angle anomalies might be the mechanism of glaucoma. Glaucoma was controlled with medical treatment in one eye, while it was resistant to medical treatment in the other eye.

In conclusion, although congenital glaucoma often is accompanied by systemic abnormalities involving tissues of neural crest origin, to the best of our knowledge, there have been no previous reports of the GGS association with neonatal-onset glaucoma. Therefore, it should be kept in mind that babies with GGS might have glaucoma.

Ophthalmologists and pediatricians must be aware of potential ocular associations of GGS such as iris and chorioretinal coloboma and carefully examine the anterior chamber angle and measure IOP in these patients to prevent irreversible visual damage.

\section{References}

1. Bostwick B, Fang P, Patel A, et al. Phenotypic and molecular characterization of focal dermal hypoplasia in 18 individuals. Am J Med Genet C Semin Med Genet 2016;172C(1):9-20. DOI: 10.1002/ ajmg.c.31473.

2. Bharani S, Thakkar S. A case report of focal dermal hypoplasiaGoltz syndrome. Indian Dermatol Online J 2013;4(3):241-243. DOI: 10.4103/2229-5178.115535.

3. Jarisch W. Zur lehre von den hautgeschwulsten. Archiv für Dermatologie und Syphilis 1894;28(1):163-165. DOI: 10.1007/ BF01843725.

4. White JC. Multiple benign cystic ephiteliomata. J Cutan Dis 1894;12:477-481.

5. Gorlin RJ, Goltz RW. Multiple nevoid basal-cell epithelioma, jaw cysts and bifid rib. A syndrome. N Engl J Med 1960;262(18):908-912. DOI: 10.1056/NEJM196005052621803.

6. Chandran S, Marudhamuthu K, Riaz R, et al. Odontogenic keratocysts in Gorlin-Goltz syndrome: a case report. J Int Oral Health 2015;7(Suppl 1):76-79.

7. Ramesh M, Krishnan R, Chalakkal P, et al. Gorlin-Goltz syndrome: case report and literature review. J Oral Maxillofac Pathol 2015;19(2):267. DOI: 10.4103/0973-029X.164557.

8. Goltz RW, Henderson RR, Hitch JM, et al. Focal dermal hypoplasia syndrome. A review of the literature and report of two cases. Arch Dermatol 1970;101(1):1-11. DOI: 10.1001/ archderm.1970.04000010003001.

9. Thomas JV, Yoshizumi MO, Beyer CK, et al. Ocular manifestations of focal dermal hypoplasia syndrome. Arch Ophthalmol 1977;95(11):1997-2001. DOI: 10.1001/archopht.1977.04450110091009.

10. Prenner JL, Ciaccia S, Capone A, et al. Retinal detachment in focal dermal hypoplasia. Eur J Ophthalmol 2004;14(2):166-168. DOI: 10.1177/112067210401400216.

11. Tenkir A, Teshome S. Goltz syndrome (focal dermal hypoplasia) with unilateral ocular, cutaneous and skeletal features: case report. BMC Ophthalmol 2010;10(1):28. DOI: 10.1186/ 1471-2415-10-28.

12. Young MP, Sawyer BL, Hartnett ME. Ophthalmologic findings in an 18-monthold boy with focal dermal hypoplasia. J AAPOS 2014;18(2):205-207. DOI: 10.1016/j.jaapos.2013.11.015.

13. Moramarco A, Himmelblau E, Miraglia E, et al. Ocular manifestations in Gorlin-Goltz syndrome. Orphanet J Rare Dis 2019;14(1):218. DOI: 10.1186/s13023-019-1190-6.

14. Taylor SF, Cook AE, Leatherbarrow B. Review of patients with basal cell nevus syndrome. Ophthalmic Plast Reconstr Surg 2006;22(4):259-265. DOI: 10.1097/01.iop.0000225421.60264.68.

15. Lasocki AL, Stark Z, Orchard D. A case of mosaic Goltz syndrome (focal dermal hypoplasia) in a male patient. Australas J Dermatol 2011;52(1):48-51. DOI: 10.1111/j.1440-0960.2010.00662.x.

16. Gisseman JD, Herce HH. Ophthalmologic manifestations of focal dermal hypoplasia (Goltz syndrome): a case series of 18 patients. Am J Med Genet C Semin Med Genet 2016;172C(1):59-63. DOI: 10.1002/ ajmg.c. 31480 .

17. Wiggins RE, Tomey KF. The results of glaucoma surgery in aniridia. Arch Ophthalmol 1992;110(4):503-505. DOI: 10.1001/archo pht.1992.01080160081036.

18. Tesser PM. An iris coloboma preventing pigmentary glaucoma. Arch Ophthalmol 2003;121(7):1055-1056. DOI: 10.1001/archopht.121.7.1055. 